\title{
Asthma and thunderstorms: description of an epidemic in general practice in Britain using data from a doctors' deputising service in the UK
}

\author{
Jonathan Higham, Katherine Venables, Emil Kopek, Madhavi Bajekal
}

\begin{abstract}
Objective-To describe the areas affected and the scale of an epidemic of thunderstorm associated asthma on the night of 24/25 June 1994 and to explore the spatial and temporal relationship between the thunderstorm and the associated epidemic.

Setting-The 29 offices of a deputising service for general practitioners' (GP) out of hours calls (Healthcall). At the time of the storm the deputising service provided out of hours cover for about 8500 out of about 30000 GPs in England, Scotland, and Wales.
\end{abstract}

Methods-Patients who phoned the Healthcall offices to request a home visit were categorised as "asthma" or "other causes" based on their presenting complaint. The number of calls on the night of 24/25 June 1994 was compared in areas affected by thunderstorms and areas not affected by thunderstorms and with the night of $17 / 18$ June 1994 , when there were no thunderstorms.

Results-A large area of the south and east of England was affected by an epidemic of asthma closely related both temporally and spatially with the thunderstorms on 24/25 June 1994. The pooled MantelHaenszel estimate for the risk of asthma in thunderstorm affected areas compared with the control night was 6.36 (95\% confidence interval $4.97,8.32$ ) compared with a value of $1.01(0.80,1.27)$ for those not exposed. Extrapolation suggests about 1500 extra patients were likely to have requested a visit from a GP that night because of epidemic asthma.

Conclusions-Under certain circumstances thunderstorms are associated with asthma and can affect many patients. Deputising services are a useful source of data for the investigation of epidemics in primary care.

\section{( $(\mathcal{E}$ Epidemiol Community Health 1997;51:233-238)}

On the night of Friday 24 June 1994, one of us $(\mathrm{JH})$ was on call for the local office of a deputising service and was asked by the telephone controller to come and help with an "epidemic of hayfever with difficulty in breathing". That night there were widespread thunderstorms across south east and central England. This was associated with a sudden increase in the number of patients with asthma who attended accident and emergency departments. ${ }^{1-3}$ The association between asthma and thunderstorms has been noted before in Birmingham $^{4}$ and Nottingham ${ }^{5}$ in the United Kingdom and Melbourne ${ }^{6}$ in Australia. There are also apparently anecdotal reports from Africa. ${ }^{7}$ Initial reports suggested that this episode was on an unprecedented scale; there being about a thousand excess attendances at accident and emergency departments. ${ }^{1}$

Various causes have been suggested for the relationship between thunderstorms and epidemics of asthma. During the Birmingham epidemic high concentrations of fungal spores from Didymella exitialis and Sporobolomyces species were noted. ${ }^{4} D$ exitialis sensitivity has been implicated in individual patients who develop asthma in summer after thunderstorms. ${ }^{8}$ However skin testing of patients affected during the Birmingham outbreak showed they were much more likely to be sensitive to grass pollen than fungal spores. ${ }^{9}$ Studies in Melbourne have implicated rye grass pollen as the causative agent. ${ }^{6}$ Grass pollen is not usually respirable but it has been suggested that the rainfall associated with thunderstorms might fragment pollen grains by osmotic shock, producing respirable submicronic particles capable of provoking asthma in previously sensitised hayfever sufferers. ${ }^{10}$

This study aimed to describe the areas affected and to explore the temporal and spatial relationship between the thunderstorm and the associated cases of asthma. General practitioners (GPs) in some urban areas employ deputising services to provide emergency cover for their patients in the evenings and at weekends. Doctors from the deputising service either visit the patients in their own homes or, increasingly, see them in emergency medical centres. For this study we used data from the doctor's deputising service provided by Healthcall to evaluate the impact of the thunderstorm on primary care and describe the extent and timescale of the epidemic. Thus, the offices of Healthcall were used in a way analogous to the sentinel practices of the Royal College of General Practitioners research unit spotter practice system. Previous studies have been based in hospital accident and emergency departments. The use of data from the deputising service allows central data collection and makes the identifying and tracking epidemics easier as well as covering a wider population.

\section{Method}

Data were collected from each of the 29 offices of the deputising service provided by Healthcall 


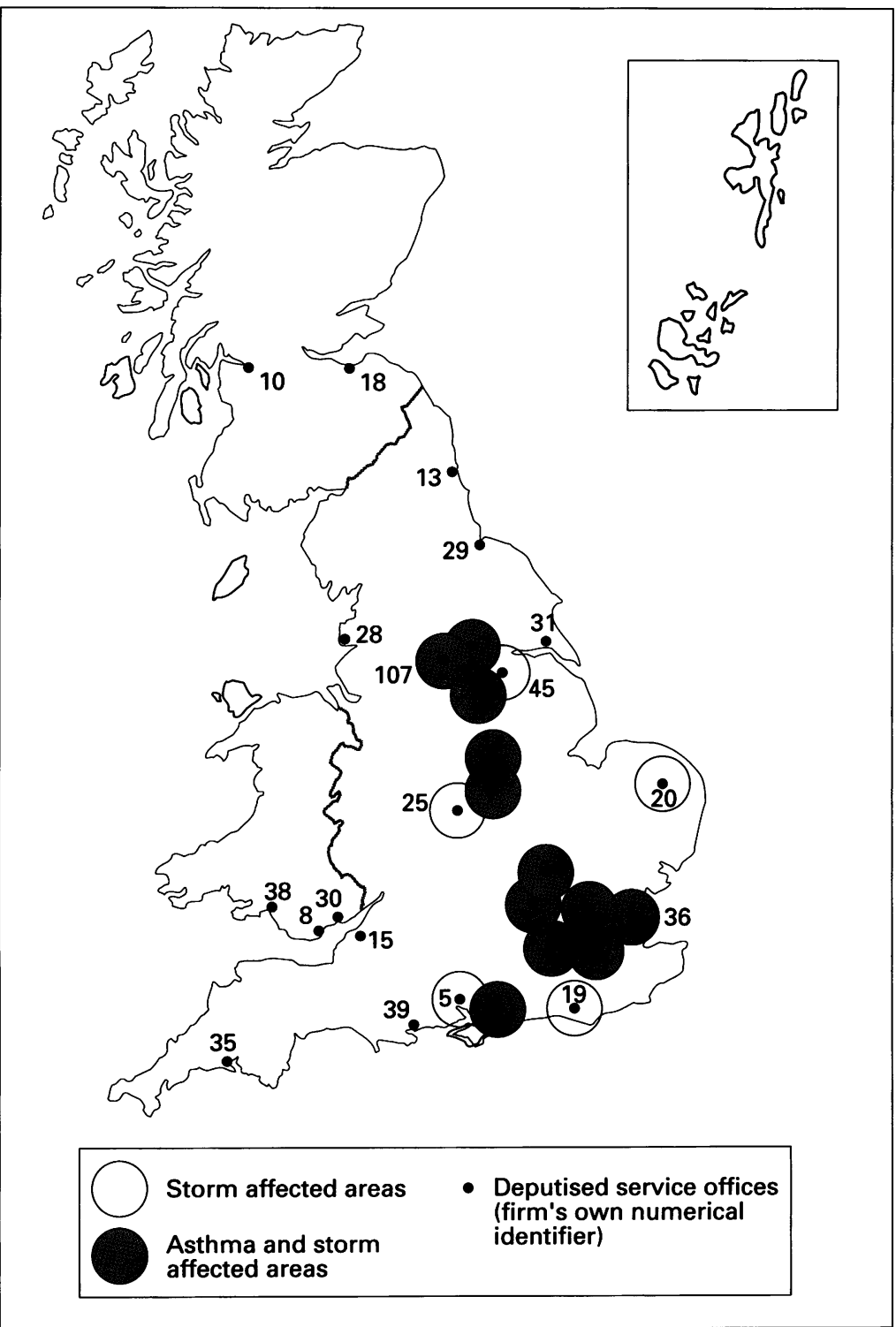

Figure 1 Map showing areas affected by thunderstorms and epidemic asthma.

in England, Scotland, and Wales. Each office covers quite a large area. For example, the Luton office also covers the surrounding towns of Milton Keynes, Stevenage, and Watford. The population covered may vary from about 100000 to over 500000 . Patients' requests for visits made between 1900 hours on Friday 24 June and 0700 hours on Saturday 25 June 1994 were recorded. The figures for the night of $17 /$ 18 of June 1994 were also recorded to provide

\section{KEY POINTS}

- Thunderstorms may be associated with episodes of asthma that have an effect on primary as well as secondary care.

- Patients may present complaining of hayfever with breathing difficulties as well as asthma.

- The intensity of the thunderstorm (number of lightning strikes) is correlated with the increase in number of patients with asthma. a control except for Blackpool, where the figures for this night were unavailable and figures for the night of 18/19 were used instead. For each call the time the call was received and the age, sex, and presenting complaint of the patient were noted. The information was recorded on a standard record sheet by deputising service staff.

The patient's own presenting complaint as recorded by the telephone operator was used for the case definition. A broad inclusive case definition was required since many patients were unaware that they were suffering with asthma. Calls for asthma were defined as those whose presenting complaint included the key words "asthma", "difficulty in breathing", "hayfever with difficulty in breathing", "short of breath", or "wheeze". Cases where additional details made asthma unlikely such as "chest pain with difficulty in breathing" were excluded as were "cough" or "hayfever" alone. Thus, the "asthma" group is likely to include most cases of epidemic asthma but is likely also to include a number of other patients with respiratory and cardiovascular conditions. Preliminary studies by $\mathrm{Dr}$ Premaratne of $\mathrm{St}$ Thomas's Hospital and Ms Austin, information manager of Greenwich Healthcare trust (personal communication), based on patients in accident and emergency departments, suggest that these definitions will cover most affected patients during epidemic conditions (49 of 50 patients identified in this way proved to have epidemic asthma on the night of $24 / 25$ June 1994 at the Greenwich District and Brook General hospital), although not in non-epidemic conditions when the keyword "asthma" alone was sufficient. In the rest of this paper the word "asthma" refers to patients defined in this way.

The Meteorological Office supplied data on thunderstorm activity using the arrival time difference (ATD) sferics (lightning flashes) system. This allows the position and time of a lightning discharge to be calculated. A lightning flash releases a unique radio signal, the waveform of which is recorded at each detector station. The time difference between them allows the position of the lightning flash to be calculated by triangulation. The Meteorological Office provided the number of lightning strikes per hour within a 10,20,30 and $50 \mathrm{~km}$ radius of each office of the deputising service. The reports between 1900 and 0700 hours British Standard Time were used to identify those areas affected and those unaffected by the thunderstorm. All offices with more than two lightning strikes in one hour within $20 \mathrm{~km}$ were defined as serving thunderstorm affected areas.

Odds ratios with $95 \%$ confidence intervals (CI) were calculated for the risk of asthma on the night of the thunderstorm relative to the control night for each office of the deputising service. A nominal value of 0.5 was given to all five areas with no cases of asthma to allow odds ratios with $95 \%$ CIs to be calculated. Areas affected by epidemic asthma were defined as those where the lower limit of the $95 \%$ CI around the odds ratio was greater than one. 
Table 1 Number of patients affected by asthma and peak number of lightning strikes within $20 \mathrm{~km}$ by deputising service office

\begin{tabular}{|c|c|c|c|c|c|c|c|c|c|}
\hline & \multicolumn{3}{|c|}{ Control night $17 / 18$ fune } & \multicolumn{3}{|c|}{ Thunderstorm night 24/25 fune } & \multirow{2}{*}{$\begin{array}{l}\text { Peak } \\
\text { lightning }\end{array}$} & \multirow{2}{*}{\multicolumn{2}{|c|}{ OR $(95 \% C I)$}} \\
\hline & Asthma & Total & $\%$ asthma & Asthma & Total & $\%$ asthma & & & \\
\hline Portsmouth (37) & 4 & 51 & 8 & 13 & 54 & 24 & \multirow{18}{*}{\multicolumn{3}{|c|}{\begin{tabular}{ccl}
35 & 3.7 & $(1.1,12.3)$ \\
34 & 24 & $(1.3,424)$ \\
31 & 14.2 & $(5.4,37.1)$ \\
29 & 6 & $(2.5,14.6)$ \\
25 & 9.9 & $(1.2,81.7)$ \\
22 & 3.4 & $(1.3,8.8)$ \\
19 & 17.5 & $(0.9,332)$ \\
16 & 30.5 & $(4,232)$ \\
10 & 4.7 & $(2,11.2)$ \\
9 & 7.8 & $(2.9,20.9)$ \\
7 & 5.5 & $(2.1,14.8)$ \\
7 & 2.4 & $(0.8,7.4)$ \\
4 & 7.6 & $(4.5,12.9)$ \\
4 & 3.1 & $(0.9,10.6)$ \\
3 & 7.7 & $(0.4,157)$ \\
3 & 5 & $(2.1,11.9)$ \\
3 & 2.7 & $(0.8,9.6)$ \\
Pooled Mantel-Haenzel estimates & \multicolumn{3}{c}{ C.36 (4.97, 8.32) }
\end{tabular}}} \\
\hline Huddersfield/Halifax (107) & 0 & 40 & 0 & 10 & 45 & 22 & & & \\
\hline Leicester (11) & 5 & 77 & 6 & 78 & 157 & 50 & & & \\
\hline Sheffield (9) & 8 & 114 & 7 & 42 & 135 & 31 & & & \\
\hline Bexley (22) & 1 & 27 & 4 & 11 & 40 & 28 & & & \\
\hline Leeds (7) & 6 & 75 & 8 & 23 & 101 & 23 & & & \\
\hline Brighton (19) & 0 & 37 & 0 & 5 & 28 & 18 & & & \\
\hline Croydon (26) & 1 & 62 & 2 & 27 & 81 & 33 & & & \\
\hline Nottingham (14) & 7 & 83 & 8 & 36 & 119 & 30 & & & \\
\hline Luton (4) & 5 & 84 & 6 & 37 & 112 & 33 & & & \\
\hline Southend (36) & 7 & 66 & 11 & 35 & 89 & 39 & & & \\
\hline Coventry (25) & 5 & 58 & 9 & 12 & 64 & 19 & & & \\
\hline GP Relief, London E10 (32) & 19 & 249 & 8 & 98 & 254 & 39 & & & \\
\hline Southampton (5) & 4 & 38 & 11 & 12 & 45 & 27 & & & \\
\hline Norwich (20) & 0 & 23 & 0 & 3 & 24 & 13 & & & \\
\hline Ruislip (33) & 7 & 84 & 8 & 33 & 106 & 31 & & & \\
\hline Doncaster (45) & 4 & 24 & 17 & 13 & 37 & 35 & & & \\
\hline Totals & 83 & 1192 & 7 & 488 & 1491 & 33 & & & \\
\hline Bournemouth (39) & 0 & 19 & 0 & 2 & 22 & 9 & 1 & 4.8 & $(0.2,105)$ \\
\hline Blackpool (28) & 5 & 56 & 9 & 2 & 35 & 6 & 1 & 0.6 & $(0.1,3.4)$ \\
\hline Hull (31) & 0 & 54 & 0 & 3 & 77 & 4 & 0 & 5.1 & $(0.3,101)$ \\
\hline Newport (30) & 1 & 34 & 3 & 7 & 34 & 21 & 0 & 8.6 & $(1,73.9)$ \\
\hline Glasgow (10) & 3 & 121 & 2 & 7 & 107 & 7 & 0 & 2.8 & $(0.7,10.9)$ \\
\hline Plymouth (35) & 2 & 48 & 4 & 3 & 37 & 8 & 0 & 2 & $(0.3,12.6)$ \\
\hline Newcastle (13) & 9 & 133 & 7 & 9 & 131 & 7 & 0 & 1 & $(0.4,2.6)$ \\
\hline Bristol (15) & 4 & 57 & 7 & 3 & 61 & 5 & 0 & 0.7 & $(0.1,3.2)$ \\
\hline Swansea (38) & 7 & 41 & 17 & 3 & 27 & 11 & 0 & 0.6 & $(0.1,2.6)$ \\
\hline Edinburgh (18) & 4 & 53 & 8 & 1 & 35 & 3 & 0 & 0.4 & $(0,3.4)$ \\
\hline Middlesbrough CHS (29) & 10 & 87 & 11 & 6 & 116 & 5 & 0 & 0.4 & $(0.1,1.2)$ \\
\hline Cardiff (8) & 7 & 56 & 13 & 2 & 55 & 4 & & 0.3 & $(0.1,1.3)$ \\
\hline Totals & 52 & 759 & 7 & 48 & 737 & 7 & & 1.01 & $(0.8,1.27)$ \\
\hline
\end{tabular}

All values of 0 were given a value of 0.5 to allow odds ratios to be calculated.

Pooled Mantel-Haenszel estimates with 95\% test based CIs were calculated for grouped analyses. ${ }^{11}$

\section{Results}

Figure 1 shows the locations of the 29 deputising service offices with the firm's own numerical identifiers. Seventeen of the 29 offices were in areas affected by the thunderstorm on 24/25 June 1994 and are indicated by light shading. Twelve of these 17 were also affected by epidemic asthma as defined above and are indicated by dark shading.

For each office the calls for asthma on the night of June 24/25 were compared with the control night of the $17 / 18$ (table 1 ). In the 17 areas affected by the storm all odds ratios for asthma were greater than 1 and the five highest odds ratios were all in this group. In the areas with two or fewer lightning strikes per hour

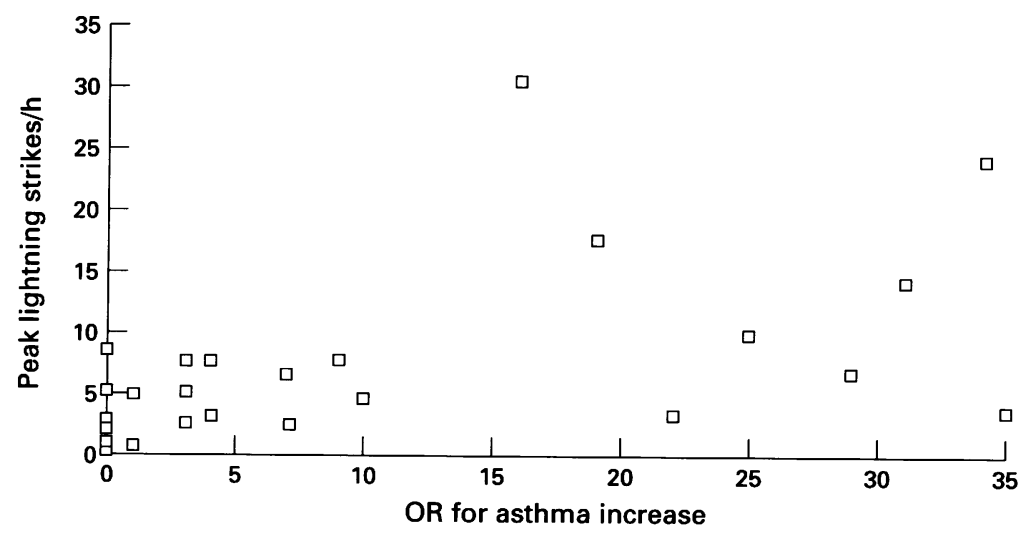

Figure 2 Scattergram showing the relationship between the odds ratio for an increase in asthma and the peak number of lightning strikes. there were no significant excesses of asthma although Newport was on the borderline with an odds ratio of 8.6 (95\% CI 1, 73.9).

On 24/25 June there were 2228 calls to the 29 offices, of which $24 \%$ (536) were for asthma (table 1) while on the control night there were 1951 calls of which 7\% (135) were for asthma. The excess on 24/25 June occurred in the 17 areas affected by the storm. These 17 offices reported 1491 calls, of which $33 \%$ (488) were for asthma, compared with $7 \%(48 / 737)$ in unaffected areas.

The pooled Mantel-Haenszel estimate for thunder affected offices of the deputising service was $6.36(4.97,8.32)$ while for those not exposed the odds ratio was $1.01(0.80,1.27)$. This means that a significant increase in asthma on the night of 24/25 June compared with 17/ 18 June occurred only in the areas affected by the thunderstorm. As the $95 \%$ CIs for the two groups do not overlap the difference in the pooled odds ratios is statistically significant.

The odds ratios for an increase in number of asthma cases correlated with the peak number of lightning strikes per hour within $20 \mathrm{~km}$ so that the areas with the greatest number of lightning strikes were those with the greatest increase in asthma cases. (Spearman correlation coefficient $\mathrm{r}=0.66 \mathrm{p}<0.0001$ ) (fig 2).

Figure 3 shows the evolution of the epidemic. Offices in areas affected by the thunderstorm were grouped into four geographical groups: South Coast (Southampton, Portsmouth, Brighton), London (Croydon, Ruislip, Bexley, Luton, Southend, E10), East Midlands (Coventry, Leicester, Nottingham and Norwich), and Northern (Leeds, Doncaster, Halifax/Huddersfield, and Sheffield). The timings of the thunderstorms are shown on the histograms. 
Table 2 Age and sex distribution of patients with asthma in areas affected and not affected by thunderstorm on 241 25 and on 17/18 Fune 1994

\begin{tabular}{cccccc}
\hline & \multicolumn{2}{l}{$\begin{array}{l}\text { Thunder } \\
\text { 24/25* }\end{array}$} & & & \multicolumn{2}{l}{$\begin{array}{l}\text { Non-thunder } \\
\text { 24/25 and 17/18† }\end{array}$} \\
\cline { 2 - 3 } \cline { 5 - 6 } Age $(y)$ & Male & Female & & Male & Female \\
\hline $0-9$ & 50 & 20 & & 44 & 28 \\
$10-19$ & 39 & 17 & & 11 & 7 \\
$20-29$ & 86 & 74 & & 8 & 13 \\
$30-39$ & 59 & 53 & & 5 & 15 \\
$40-49$ & 26 & 21 & & 3 & 6 \\
$50-59$ & 10 & 6 & & 4 & 6 \\
$60-69$ & 6 & 8 & & 3 & 2 \\
$70-79$ & 2 & 3 & & 6 & 9 \\
$80+$ & 3 & 4 & & 5 & 6 \\
& 281 & 206 & 89 & 92 \\
\hline
\end{tabular}

* Excludes 1 patient with age not recorded.

† Excludes 2 patients, 1 age and the other sex not recorded.
There was an onset of a high frequency of asthma calls (defined as greater than $20 \%$ of the total number of calls that hour) between one and two hours after the thunderstorms at $2000,2100,2100$, and 2300 hours respectively. There was a tendency for the calls to come sooner in areas where the increase in number of asthma cases was greater.

Details of the 488 patients with asthma from areas affected by the thunderstorm on $24 / 25$ June 1994 were analysed. The male:female ratio was $1.35: 1$. Most of the patients were aged in their 20s and 30s (table 2, fig 4). Hayfever was mentioned by $196(40 \%)$ patients and asthma by $185(38 \%)$ as part of their
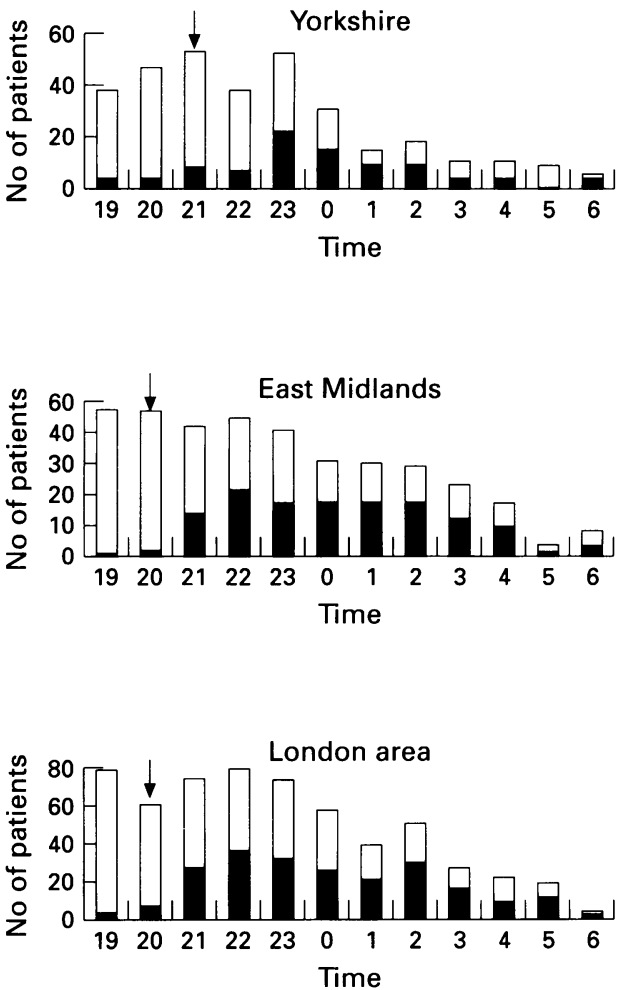

South Coast

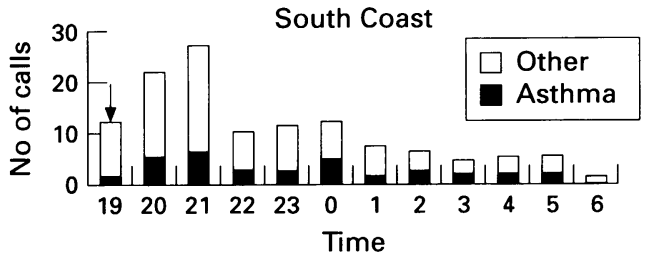

Figure 3 Map showing the evolution of the epidemic of asthma related to thunderstorms. 


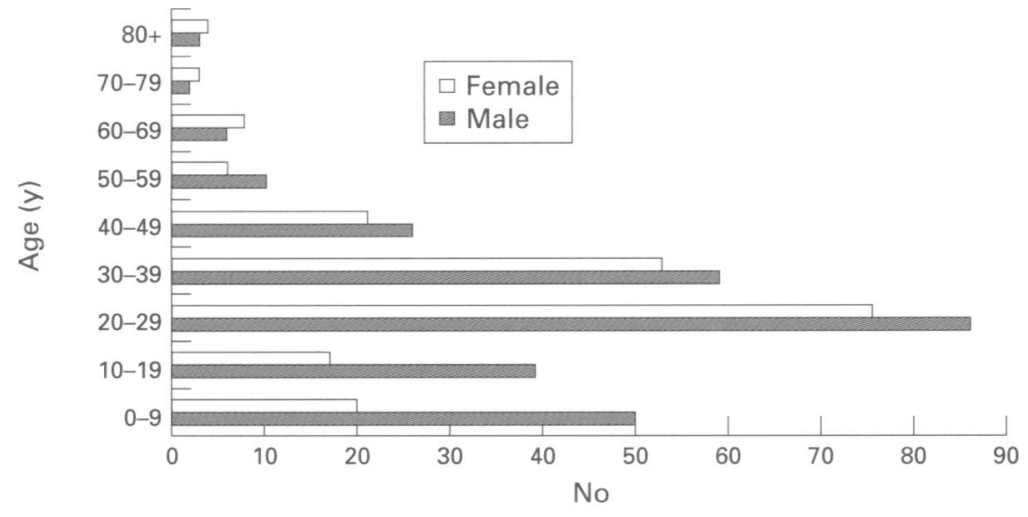

Figure 4 Age and sex distribution of the "asthma" patients in the areas affected by thunderstorms on 24/25 fune 1994.

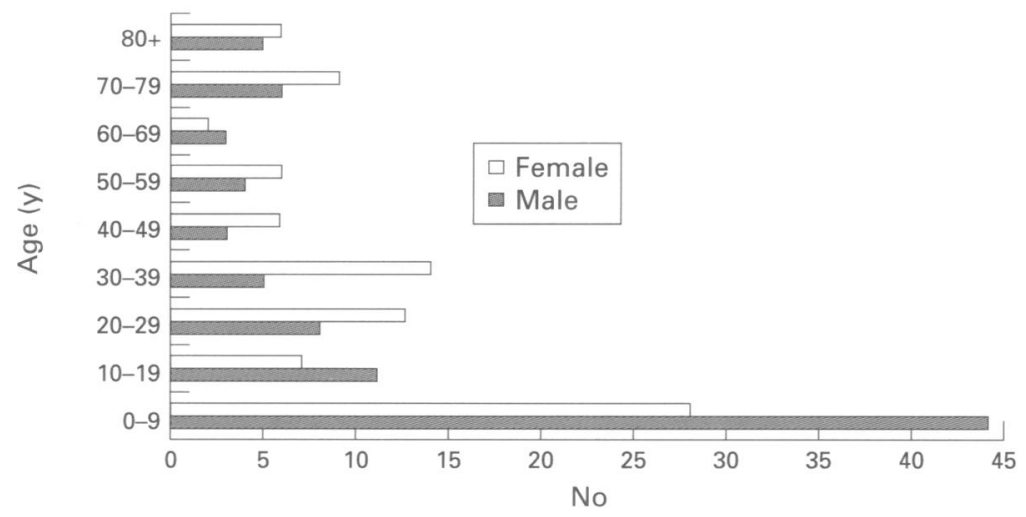

Figure 5 Age and sex distribution of "asthma" patients in areas not affected by thunderstorms on 24/25 fune 1994 and 17/18 fune 1994 combined.

presenting complaint. Among affected women between the ages of 15 and 44 years, 15 of 147 mentioned they were pregnant.

In areas unaffected by the thunderstorm and on the control day combined there were 183 asthma patients. The male female ratio was 1 : 1 and the age range more widely distributed with a higher proportion of the young and the elderly (see table 2 , fig 5 ). Eleven (6\%) patients mentioned hayfever and $112(61 \%)$ patients mentioned asthma as part of their presenting complaint. None of the 32 affected women aged between 15 and 44 reported they were pregnant. Some patients complained of both asthma and hayfever. Three patients details are not complete; in two the age and in one the sex was not recorded.

Deputising services are employed by GPs to answer calls from patients outside normal surgery hours. At the time of the storm about $8500 \mathrm{GP}$ principals out of about 30000 in England, Scotland, and Wales subscribed to Healthcall, the deputising service studied in this investigation. Deputising services generally serve urban areas where there is a sufficient concentration of doctors and patients to make such a service viable. Among urban GPs about two thirds use deputising services. Subscribing GPs use the deputising services for about $90 \%$ of their out of hours calls (personal communication, Dr Kaiper-Holmes, Healthcall). Using these figures we can extrapolate and form a rough estimate of the number of excess calls attributable to the thunderstorm. The excess number of calls seen by the deputising service was 401 ( 536 on $24 / 25$ June minus 135 on $17 / 18$ - control night). If the subscribing doctors were using the deputising service for $90 \%$ of their calls that night, then the excess number of calls among doctors who subscribe to Healthcall would be $446(401 \times 10 / 9)$. The proportion of GPs using Healthcall in England, Scotland, and Wales was about $28 \%$ (8500/ 30000 ). In which case the number of calls due to epidemic asthma in general practice would be about $1572(30000 / 8500) \times(536-135) \times(10 /$ 9).

Thus, assuming that practices using the deputising service were evenly distributed between the areas affected and unaffected by the thunderstorm, and that rural areas were affected equally to urban areas, some 1500 extra visits to patients with asthma occurred because of the epidemic. Some of these patients may also have attended accident and emergency departments. An unknown number of others may have been affected but not sought medical help until the next day or not at all.

\section{Discussion}

In this study we have been able to show that the epidemic of asthma symptoms was closely associated with the thunderstorm. The epidemic affected an area from the South Coast extending past London up through the East Midlands to Yorkshire. The areas more severely affected by the thunderstorm as measured by the Meteorological Office arrival time difference (ATD) system experienced a greater increase in asthma cases. The degree of association leaves little doubt that the thunderstorm was in some way responsible for the epidemic of asthma.

A broad case definition based on the patients presenting complaint was used. Any bias due to including patients with other respiratory or cardiovascular conditions would be expected to underestimate rather than overestimate the odds ratios. The precise factor that precipitates asthma in susceptible subjects is unknown so the lightning strikes are a proxy measure for this responsible factor. The peak number of lightning strikes within a $20 \mathrm{~km}$ radius was used, but lightning strikes within 10, 20, 30, and $50 \mathrm{~km}$ and peak or total lightning strikes all correlated closely with each other and gave similar results.

The age and sex distributions of the patients affected were similar to those in patients who had attended accident and emergency departments in previous epidemics. The male: female ratio and the mean age were 1.35:1 and 28 years compared with respective values of 1.4 and 24.7 years in Birmingham in $1983^{4}$ and 1.35 and 32 years in the 1994, Thames regions accident and emergency trainees study. ${ }^{2}$ As in the accident and emergency study, ${ }^{2}$ a high proportion $(40 \%)$ of patients mentioned hayfever as part of their presenting complaint.

Deputising service records have a number of strengths for the study of rapidly evolving epidemics in general practice. They cover large populations, usually of several hundred thou- 
sand people, which allows evolving epidemics to be detected. An individual general practice on the night of the 24 June 1994 is unlikely to have had more than one or two patients with "epidemic asthma" and the phenomenon might easily have passed unrecorded, but for the impact on facilities serving large populations such as ambulance services, accident and emergency departments, and deputising services. Deputising service data are particularly strong on the time the call is received and acted on, and also include the name, address, sex, and presenting complaint of the caller. The doctor's assessment is also recorded, although not in any systematic way. For this reason this study used the patient's presenting complaint.

The main weaknesses of deputising service data are that they are not computerised and that they cover only emergency calls outside office hours (during the evenings, at night, and after Saturday midday on the weekends). The lack of computerisation prevented more than one night being used for the control in this study. If this information were computerised and the data recorded in a standardised format it would be possible to use it easily to study the evolution of epidemic illnesses in primary care. Deputising service staff report that illnesses such as influenza and media induced panics such as that over necrotising fasciitis can be readily followed minute by minute and hour by hour as they pass across the country.

Previous studies have concentrated on single centres or small groups of neighbouring hospitals. It is clear from this study that this epidemic of thunderstorm associated asthma affected a very wide area from the South Coast to Yorkshire in a short period of time and involved over a thousand patients in general practice. The widespread nature of the epidemic means that if local emergency services are overwhelmed they are unlikely to be able to call on neighbouring services for support since they too are likely to be under pressure. ${ }^{2}$ This study also shows that epidemic asthma can have a pronounced effect on primary care as well as accident and emergency departments.

Further research is required to study which kind of patients are affected by thunderstorm associated asthma and which atmospheric conditions produced by thunderstorms are responsible for these outbreaks so that they can be forecast and suitable preparations made.

We thank Dr Kaiper-Holmes of Healthcall for his support and the calls by the Healthcall staff for copying out the details of the calls by hand, Professor Collier and Dr Archibald of the meteorological office for advice and providing the automatic thunderstorm detection data, Ms
with case definition.

with case definition. $\mathrm{JH}$ was supported by a research fellowship in general
from North West Thames Regional Health Authority.

1 Murray V, Venables $\mathrm{K}$, Laing-Morton $T$, Partridge $M$, Thurston J, Williams D. Epidemic of asthma possibly related to thunderstorms. BMF 1994;309:131-32.

2 Thames Regions Accident and Emergency Trainees Association, Davidson AC, Emberlin J, Cook AD, Venables Sociation, Davidson AC, Emberlin J, Cook $A D$, Venables KM. A major outbreak of asthma associated with a thunderstorm: experience of accident and emergency departments

3 Celenza A, Fothergill J, Kupek E, Shaw RJ. Thunderstorm associated asthma: a detailed analysis of environmental factors. $B M \mathcal{F}$ 1996;312:604-7.

4 Packe GE, Ayres JG. Asthma outbreak during a thunderstorm. Lancet 1985;ii:199-204.

5 Alderman PM, Sloan JP, Basran GS. Asthma and thunderstorms. Arch Emerg Med 1986;3:260-62.

6 Bellomo R, Gigliotti P, Treloar A, Holmes P, Suphioglu C, Singh M, Knox B. Two consecutive thunderstorm associated epidemics of asthma in the city of Melbourne. The possible role of rye grass pollen. Med f Aust 1992; 156:834-37.

7 Hendrick DJ. Asthma: epidemics and epidemiology. Thorax 1989;44:609-13.

8 Harries MG, Lacey J, Tee RD, Cayley GR, Newman-Taylor AJ. Didymella Exitialis and late summer asthma. Lancet 1985;i:1063-66.

9 Packe GE, Ayres JG. Aeroallergen skin sensitivity in patients with severe asthma during a thunderstorm. Lancet 1986; i:850-51.

10 Knox RB. Grass pollen, thunderstorms and asthma. Clin Exp Allergy. 1993;23:354-59.

11 Armitage P, Berry G. Statistical methods in medical research. Oxford: Blackwell Scientific Publications, 1987. 